\title{
Application of simulated annealing optimization algorithm to optimal operation of intelligent well completions in an offshore oil reservoir
}

\author{
Mohammad Hossein Raoufi • Amir Farasat • \\ Mohammad Mohammadifard
}

Received: 2 January 2014 / Accepted: 13 October 2014/Published online: 28 October 2014

(C) The Author(s) 2014. This article is published with open access at Springerlink.com

\begin{abstract}
The latest intelligent fields include intelligent well completions capable of collecting downhole data, which allow the operator to selectively control completion intervals throughout the life of a reservoir. Performance can be monitored and optimized in real time and operations can be adjusted remotely using downhole equipment. To quantify and develop this potential, we deigned an algorithm-based system which is capable of optimizing intelligent well control to decide on whether or not to utilize intelligent well technology. Simulated annealing algorithm was used for obtaining an optimum control strategy and determining an operation that maximizes the net present value (NPV). In this article, we used more than 4,000 simulation runs which were performed automatically in a reservoir simulator to optimize a cyclic production scenario with intelligent well completions. The intelligent wells were equipped with on/off inflow control valves in each zone, which were opened and closed sequentially to maximize the oil rate while not exceeding limits for water production. The results show that the application of
\end{abstract}

M. H. Raoufi $(\bowtie) \cdot$ A. Farasat · M. Mohammadifard Iranian Offshore Oil Company, (IOOC), No. 38, Touraj Street, Valiasr Ave, Modarres Crossroad, 19395 Tehran, Iran e-mail: raufi@alum.sharif.edu

A. Farasat

e-mail: a.farasat@iooc.co.ir

M. Mohammadifard

e-mail: m.mohammadifard@iooc.co.ir simulated annealing algorithm for optimization of intelligent well technology culminates in an increase in the NPV through $14 \%$ increase in cumulative oil production and a significant reduction in water production.

Keywords Intelligent wells · Smart wells · Intelligent completions · Optimization · Layered reservoirs ·

Simulated annealing · NPV · Control strategy · Cyclic production

$\begin{array}{ll}\text { Abbreviations } \\ \text { BHP } & \text { Bottomhole pressure } \\ \text { Cum } & \text { Cumulative } \\ \text { CYC } & \text { Cyclic } \\ \text { conv. } & \text { Conventional production scenario } \\ \text { G } & \text { Gas } \\ \text { ICV } & \text { Inflow control valve } \\ \text { intelligent } & \text { Intelligent production scenario } \\ \text { IW } & \text { Intelligent well } \\ \text { Lim } & \text { Limit } \\ \text { Max } & \text { Maximum } \\ \text { md } & \text { Millidarcy } \\ \text { Min } & \text { Minimum } \\ \text { NPV } & \text { Net present value } \\ \text { O } & \text { Oil } \\ \text { S } & \text { Saturation } \\ \text { SA } & \text { Simulated annealing } \\ \text { SAGD } & \text { Steam-assisted gravity drainage } \\ \text { SG } & \text { Solution gas } \\ \text { T } & \text { Temperature } \\ \text { V } & \text { Vertical } \\ \text { W } & \text { Water } \\ \text { wcut } & \text { Water cut } \\ \text { W.O. } & \text { Workover } \\ \end{array}$




\section{Introduction}

Intelligent well technology

An intelligent well is defined as an advanced well equipped with intelligent completion technology. An intelligent well completion is a system equipped with sensors and special valves installed on the production tubing, which provides the operator with continuous monitoring and adjustment of fluid flow rates and pressures, as displayed in Fig. 1.

The principle that underlies the use of flow control valves in horizontal wells is the imposition of an additional pressure drop, usually proportional to flowrate squared (Addagio-Guevera and Jackson 2008), that equalizes the uneven drawdown along the lateral to promote a more uniform fluid front movement. A considerable degree of flexibility is achieved to control each branch or section of a well independently. Since intelligent wells offer a major advance in well technology, there is a critical and growing need for a strategy to justify the appropriate deployment of this technology.

Intelligent well technology has been the subject of many studies which intended to obtain standard methodologies for calculating its advantages, (Robinson 1997; Holmes et al. 1998; Greenberg 1999; Yeten and Jalali 2001; Valvatne et al. 2003), which explain the control strategy of these devices as well as their operating principles. These benefits include improved reservoir management (Brouwer et al. 2001; Kharghoria et al. 2002; Glandt 2005) (e.g. production from layered reservoirs, thin oil rims and multiple reservoir compartments, managing water/gas coning in wells, preferable sweep efficiency during EOR, auto gas lift etc.), reservoir diagnostics and formation evaluation (Glandt 2005) (flow profiling in horizontal wells, downhole production testing), and more efficient cleanup/flowback of complex wells (Al-Khelaiwi et al. 2009).

They can also be used to selectively shutoff production/ injection from/into the different completion intervals. "Proactive" control strategy often outperforms "reactive" control strategy, which means reacting after production/ injection changes are observed in wells. A previous publication reported improved recoveries ranging between 0.2 and $1.2 \%$ of STOIIP for intelligent horizontal wells completed in a channelized reservoir (Ebadi and Davies 2006a).

All the above-mentioned studies manifest the considerable benefits of intelligent well systems, drawing the conclusion that updated methodologies are vital to ensure the optimum control for these wells. Changing configuration in reaction to unexpected events is considered to be an important advantage of an intelligent well. For example, an
Fig. 1 Schematic intelligent well completion, showing packers, inflow control valves, hydraulic and electric control lines

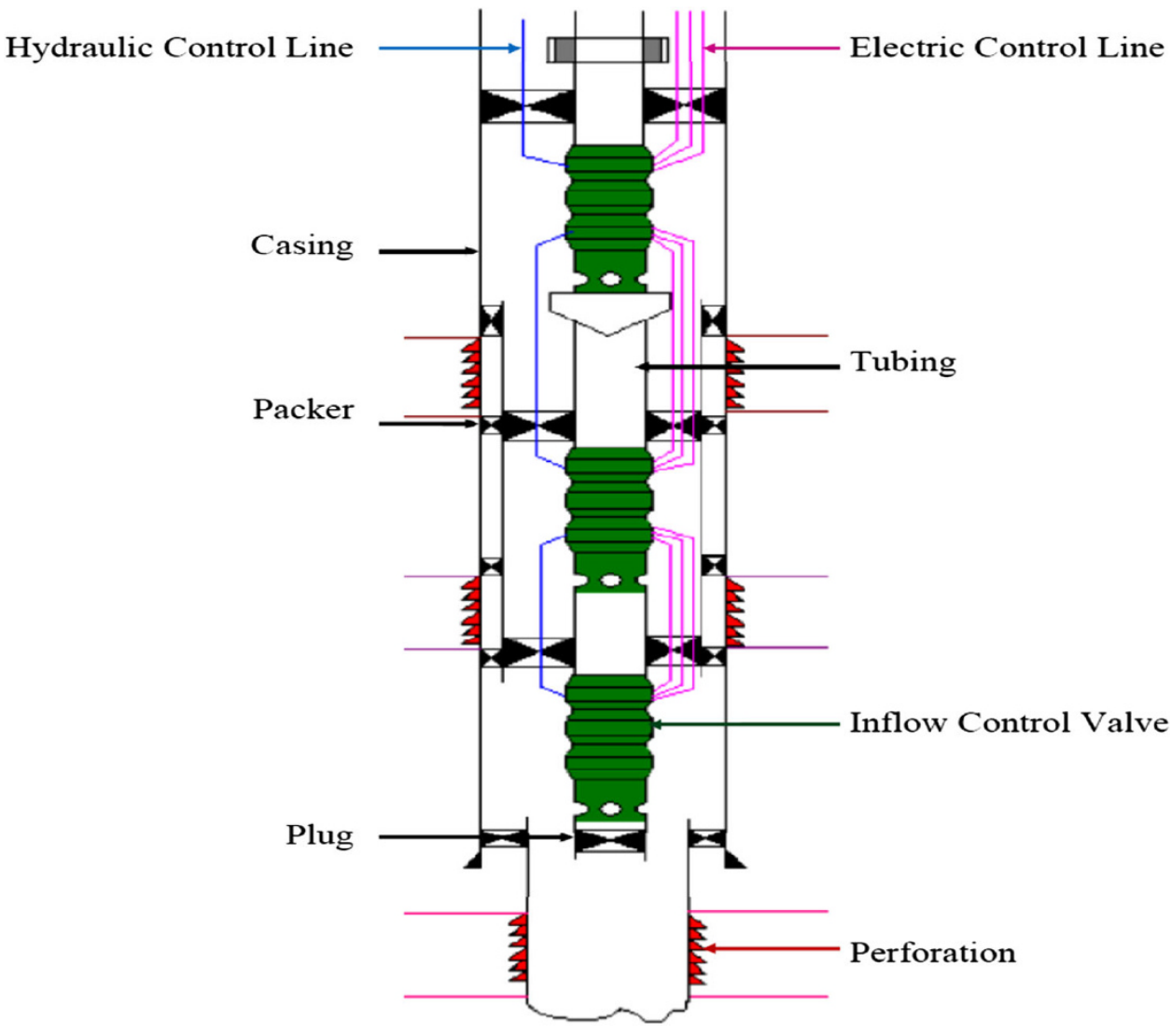


early water breakthrough in a completed zone can be mitigated by shutting off or choking down. On the other hand, shutting off the watered zone would require a workover in a conventional well, which results in increasing costs and a halt in production. Moreover, reopening a zone, after it has been shutoff, is usually not technically feasible. As a result of the additional flexibility presented by inflow control valves (ICV), intelligent well technology is able to significantly influence the net present value (NPV) of a development project.

Controlled commingled production is also accomplished by an intelligent well drilled through separate reservoir zones (Jalali et al. 1998). As an alternative, the well can be used to sequentially produce the reservoir zones with the flexibility to open and close whenever required. Tern field constitutes a quintessential example of such a sequential production scenario with intelligent wells, as described by Akram et al. (2001).

Intelligent well production optimization

The objective of optimizing the management of an oil reservoir is to devise production strategies that are economically more beneficial. However, high costs associated with such strategies in well operations, particularly in offshore reservoirs, may make some of these optimization operations unfeasible, leading to a suboptimal reservoir management process. This is exactly where the intelligent well concept stands out as an effective alternative.

The problem of optimizing the valve operation in intelligent wells has been investigated in the literature by adopting classical optimization methods such as gradient descent, conjugate gradient or nonlinear conjugate gradient methods (Yeten et al. 2002; Kharghoria et al. 2002).

The initial objective of this work is to develop an optimized methodology capable of providing an economic comparison between the use of conventional wells and intelligent wells. These comparisons provide the managers with a helpful device to decide whether or not to use intelligent wells in an oil production project. Furthermore, an optimum control of the valve operations in intelligent well systems based on simulated annealing algorithm is proposed in this study. The optimum well control by intelligent well technology is acquired via using flow control valves and pressure sensors. The main goal of our optimization is to develop a control strategy for adjusting the valves configurations existing in intelligent wells so that we are able to maximize reservoir production under some criteria.

The reservoir developers and managers have expressed increasing interest in newly developed optimization processes for intelligent well completions. As a result, diverse research methodologies have been proposed to apply optimization methods to intelligent well technology to balance production along the wellbore length, control water breakthrough, and ensure early economic oil production. Brouwer et al. (2001) proposed an optimization process based on a basic algorithm, which involved shutting well segments with the highest productivity indexes and adding the production from these segments to another well segment to balance production along the wellbore length. Optimal control theory has also been utilized to improve water production control and oil recovery (Brouwer and Jansen 2002; Dolle et al. 2002). Gai (2001) proposed an optimization method for controlling flow in a dual lateral intelligent well system. He integrated the inflow performance relationship with valve performance relationship to optimize the valve settings. Subsequently, Yeten et al. (2004) developed Gai's work (2001) and proposed a conjugate gradient algorithm for optimizing the control of a fixed number of on/off valves located in a single well. Meum et al. (2008) have used non-linear predictive control to optimize intelligent well production.

Various approaches to optimize the positions of the ICVs and the valve's flow cross-sectional area have been published recently. Network/system models have been used by some authors to optimize the valve aperture for fixed well configuration. These models were used in combination with optimization algorithms like sequential quadratic programming for application in wells for maximizing hydrocarbon recovery during the field's decline period (Elmsallati and Davies 2005). Other techniques of intelligent well optimization that have been used so far are based on reservoir simulation. These include placing ICVs in different well/reservoir geometries with varying reservoir drive mechanisms (Ebadi and Davies 2006b).

Stochastic methods are also capable of determining the global minima (in theory) but require longer computational durations. Gradient-based algorithms tend to get restricted to local minima though they are more computationally efficient. Applications of these methods range from maximizing oil recovery from simple single well models (Kharghoria et al. 2002) to complex channel-type reservoirs (Yeten et al. 2002, 2004).

Stone et al. $(2010,2011)$ have worked on the optimization of ICVs for SAGD but the technique could be translated to any well. Doublet et al. (2009) formulated a constrained optimization problem as an augmented Lagrangian saddle point problem.

Dilib et al. (2012) optimized a closed-loop strategy using a base case model, and then tested against unexpected reservoir behavior by adjusting a number of uncertain parameters in the model. They found that closedloop feedback control yields positive gains in NPV for the majority of reservoir behaviors investigated, and higher gains than the open-loop strategy since closed-loop control 
can also yield positive gains in NPV even when the reservoir does not behave as expected. Datta-Gupta et al. (2010) proposed an approach that is computationally efficient and suitable for large field scale. They used streamlines to analytically compute the sensitivity of the arrival times with respect to well rates.

More recently, Ghosh and King (2013) used simulated annealing algorithm in conjunction with a commercial reservoir simulator to maximize an objective function that captures the mean and variance in the well's estimated value to determine the optimal placement of ICVs and their inflow settings. However, they just applied their approach in a set of simple conceptual black oil reservoir models with a single producing horizontal well.

As mentioned above, the problem of optimizing intelligent wells with classical optimization methods is widely addressed in the research papers found in the literature. However, if the number of optimization variables increases owing to a large number of valves or wells, the optimization problem becomes quite complex and difficult to be tackled using classical optimization methods. That is why the development of robust control techniques to identify the optimal ICV settings is still an area of active research, particularly in the case of application of direct search methods. Hence in this paper, for the first time, we have proposed and analyzed the application of simulated annealing algorithm as the optimization method for the design and operation of intelligent well completions in a real offshore oil reservoir model unlike previous studies, in which simple conceptual reservoir models (Ghosh and King 2013) or synthetic bottom water drive model was used (Kharghoria et al. 2002).

\section{Simulated annealing}

Simulated annealing (SA) is an effective and predominant optimization algorithm used to solve non-linear optimization problems. SA is a numerical optimization technique based on the principles of thermodynamics. The method was independently described by Kirkpatrick et al. (1983), which is an adaptation of the Metropolis-Hastings algorithm, published in a paper by Metropolis et al. (1953). The algorithm in this paper simulated cooling of material in a heat bath, which is a process known as annealing.

If we heat a solid past melting point and then cool it, the structural properties of the solid depend on the rate of cooling. Large crystals will be formed if the liquid is cooled slowly enough. However, if the liquid is cooled quickly, the crystals will contain imperfections. The annealing algorithm simulates the cooling process by gradually lowering the temperature of the system until it converges to a steady, frozen state.

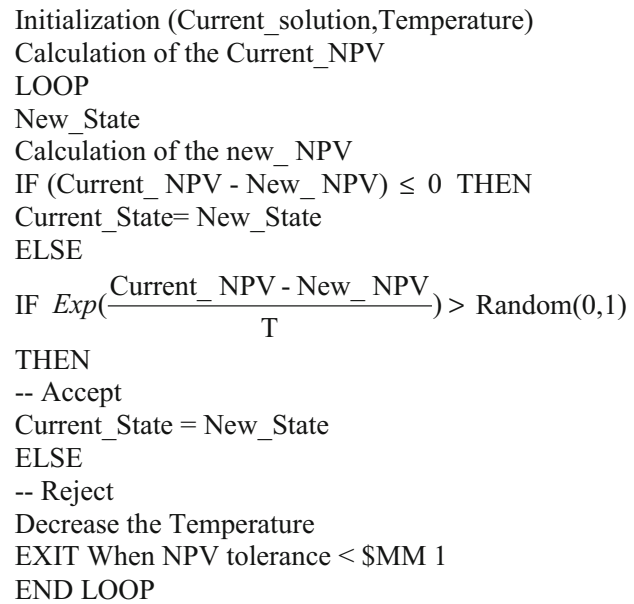

Fig. 2 Simulated annealing algorithm

SA approaches the problems similar to using a bouncing ball that can bounce over function from optimum to optimum. The algorithm starts at a high "temperature" where the temperature is an SA parameter that mimics the effect of a fast moving particle in a hot object like a hot molten metal, thereby permitting the ball to make very high bounces and being able to bounce over function to access any optimum. As the temperature is made relatively colder, the ball cannot bounce so high and it is constricted by relatively smaller ranges of movement.

In this work, since we are trying to maximize NPV, our objective function for minimization is aptly described by "-NPV". We define probability distributions of the twodirectional parameters. These distributions are called generating distributions since they generate possible optimums or states we are to explore. We define another distribution, called the acceptance distribution, which depends on the difference of objective function of the present generated optimum and the last saved lowest optimum. The acceptance distribution decides probabilistically whether to stay in a new lower optimum or to bounce out of it. All the generating and acceptance distributions depend on temperatures.

\section{SA algorithm}

The algorithm starts from a valid solution and randomly generates new states for the problem and calculates the associated NPV function. Simulation of the annealing process starts at a high fictitious temperature. A new state is randomly chosen and the difference in NPV function is calculated. If (Current_NPV - New_NPV) $\leq 0$, i.e., the NPV is higher, then this new state is accepted. This forces the system toward a state corresponding to a local or a possibly a global optimum. To get out of a local optimum, 


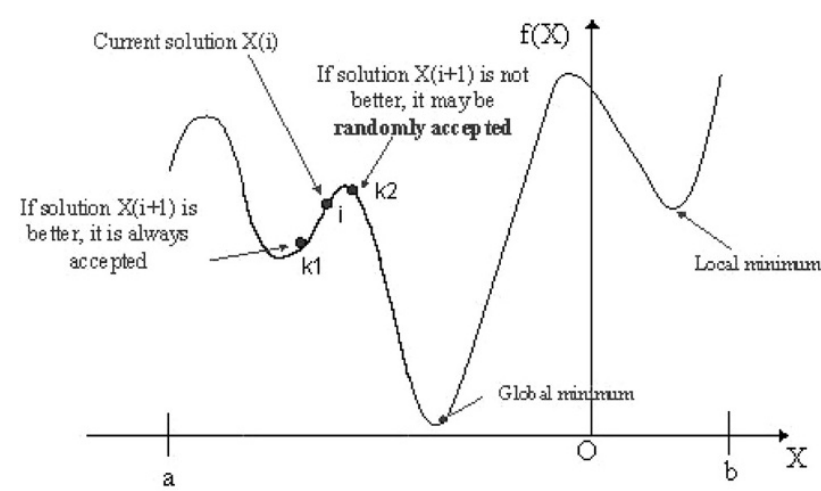

Fig. 3 Selection of a new state in simulated annealing [adapted from Kirkpatrick et al. (1983)]

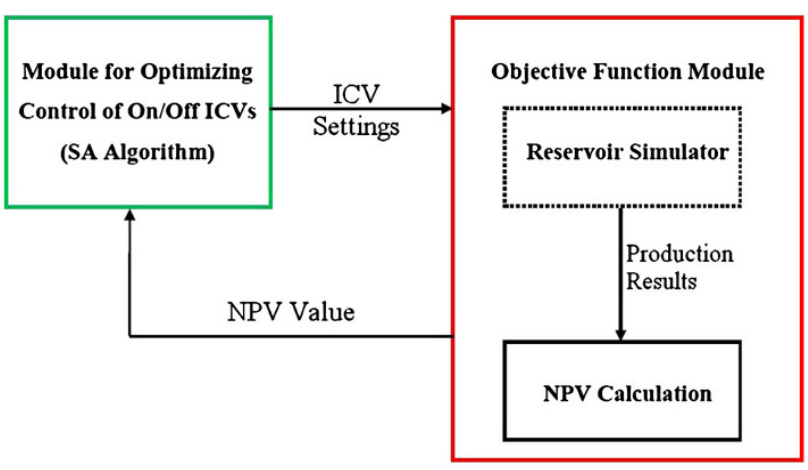

Fig. 4 Main modules of the proposed optimization system

an increase of the -NPV function is accepted with a certain probability. The simulation starts with a high temperature. This makes the left hand side of Eq. (1) close to 1.

$\operatorname{Exp}\left(\frac{\text { Current_NPV }- \text { New_NPV }}{T}\right)$

Hence, a new state with a larger NPV has a high probability of being accepted. The whole algorithm is illustrated in Fig. 2. For example, starting from state $i$, as presented in Fig. 3 , the new state $k 1$ is accepted, but the new state $k 2$ is only accepted with a certain probability. The probability of accepting a worse state is high at the beginning and decreases as the temperature decreases. For each temperature, the system must reach equilibrium and a number of new states must be tried before the temperature is reduced typically about $10 \%$. It has been shown that the algorithm is able to find the global optimum without getting stuck in a local optimum under certain conditions (Kirkpatrick et al. 1983).

\section{Hybrid optimization system for valve control}

In this paper, we have proposed a new methodology for assessing and increasing the benefits of application of intelligent wells as well as a helpful device to decide whether or not to use intelligent wells in an oil production project.

Our proposed system has three proven capabilities: first, evaluating the viability of intelligent well completion application; second, optimizing the operation of on/ off valves based on a control strategy; and third, determining an optimal configuration for the operation of valves. Figure 4 introduces a block diagram showing the modules of our proposed system. Our designed workflow manager is capable of generating data files, controlling simulations and optimizations and post-processing simulation results.

The module for optimizing valve control in intelligent wells

This module generates possible control solutions leading to an optimal configuration for the operation of valves by means of SA algorithm. These solutions represent valve control strategies at certain intervals during the production period. Each solution is sent to the objective function module (explained in "Objective function module"), where its NPV will be calculated using a reservoir simulator. The function of this module is to find the optimal configuration for a particular set of valves at specified time intervals during simulation period, which results in the highest NPV value. This is the main module of our proposed system, which is able to work properly under any configuration of on/off valves.

\section{Simulator representation of intelligent wells}

A more effective well model for reservoir simulation can be built by dividing the wellbore into segments. An alternative name for this approach is multisegment well modeling, which reflects that the wellbore fluid conditions are calculated in their own finite-difference grid analogous to the conditions in the reservoir. Meanwhile each of them has its own set of strongly coupled main variables. An exemplary implementation of this approach in a commercial blackoil simulator and its application to model two types of advanced wells were described by Holmes et al. (1998). Figure 5 shows how a multilateral well is represented by a network of such segments constructing a tree structure. Segments that represent perforated lengths of the well have connections to the reservoir. These segments are represented by an inflow performance relationship similar to conventional wells.

Other segments represent unperforated lengths of the tubing. In addition, flow-control devices like on/off valves 


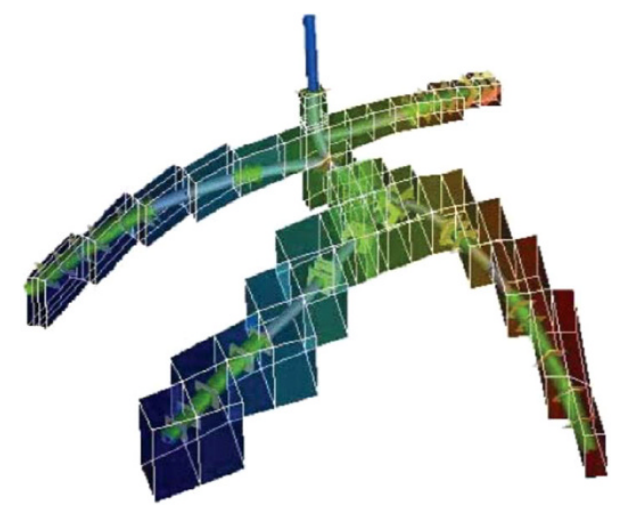

Fig. 5 A multisegment well model showing the grid cells intersected by the wellbore

are modeled considering the pressure-loss characteristics of the devices, as depicted in Fig. 6.

Objective function module

The dominant role of this module is to evaluate each solution proposed by the module for optimizing valve control. This module receives the solutions generated by the optimization process and imports them into the reservoir simulator, which models the production profile. On the basis of that production profile, this module performs the NPV calculation for each solution generated.

\section{Case study}

We used a real layered reservoir model with a cross section as displayed in Fig. 7. The main characteristic of the reservoir is its segmentation into two separate main productive layers. The upper main layer consists of nine zones, and the lower main layer consists of seven zones with dissimilar permeability and porosity. Three deviated production wells were recommended by an expert to penetrate both layers.

Reservoir and well model

The main feature of this reservoir model is the existence of two main layers with dissimilar permeability, which are isolated by shale barriers represented by a transmissibility equal to zero.

Three deviated production wells were used in this model. A $100 \%$ water-saturated region exists in the deepest part of this reservoir which forms a strong aquifer. An initial average water saturation value of 0.30 was considered for the remaining regions in the reservoir. The structure and distribution of fluids in this reservoir are displayed in Fig. 7.

\section{Geometry and grid}

This reservoir model has real characteristics and its porosity and permeability are described by maps. The reservoir consists of $33 \times 22 \times 25$ corner-point grids. Table 1 gives further details on the model geometry and grid properties and dimensions of the full model are summarized in Table 2.

\section{Reservoir rock and fluid properties}

Relative permeability and capillary pressure data are given in Table 3. Net/Gross was set equal to unity for all layers. Oil and water properties were taken directly from the reservoir fluid analysis model (see Table 4). Other required aquifer properties were taken from the neighboring simulation grid.
Fig. 6 Modeling intelligent completions by a multisegment well model
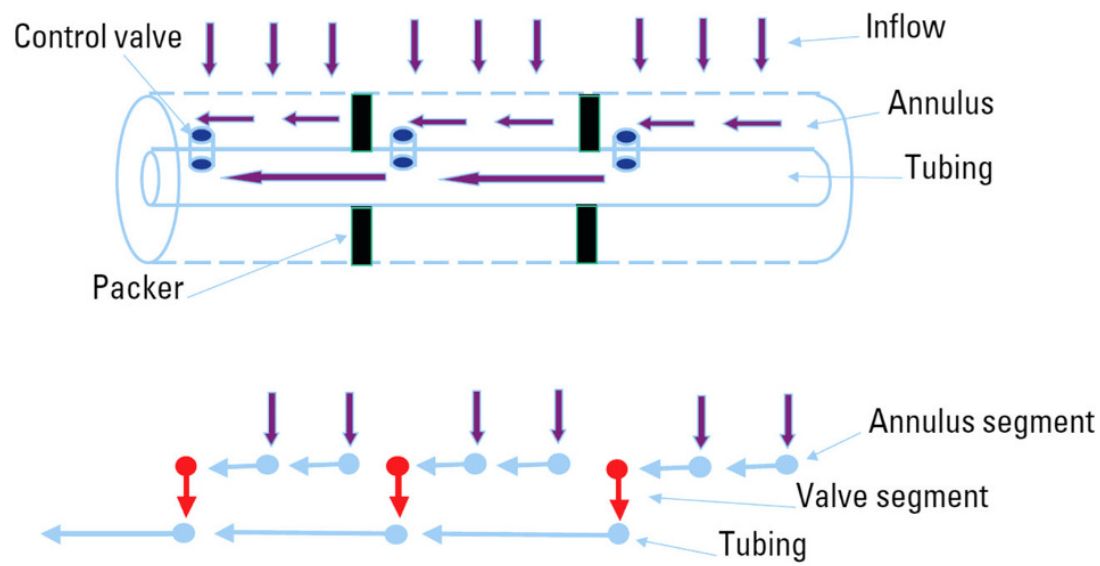
Fig. $7 \mathrm{X}-\mathrm{Z}$ cross section of the reservoir model showing saturation distribution in different layers

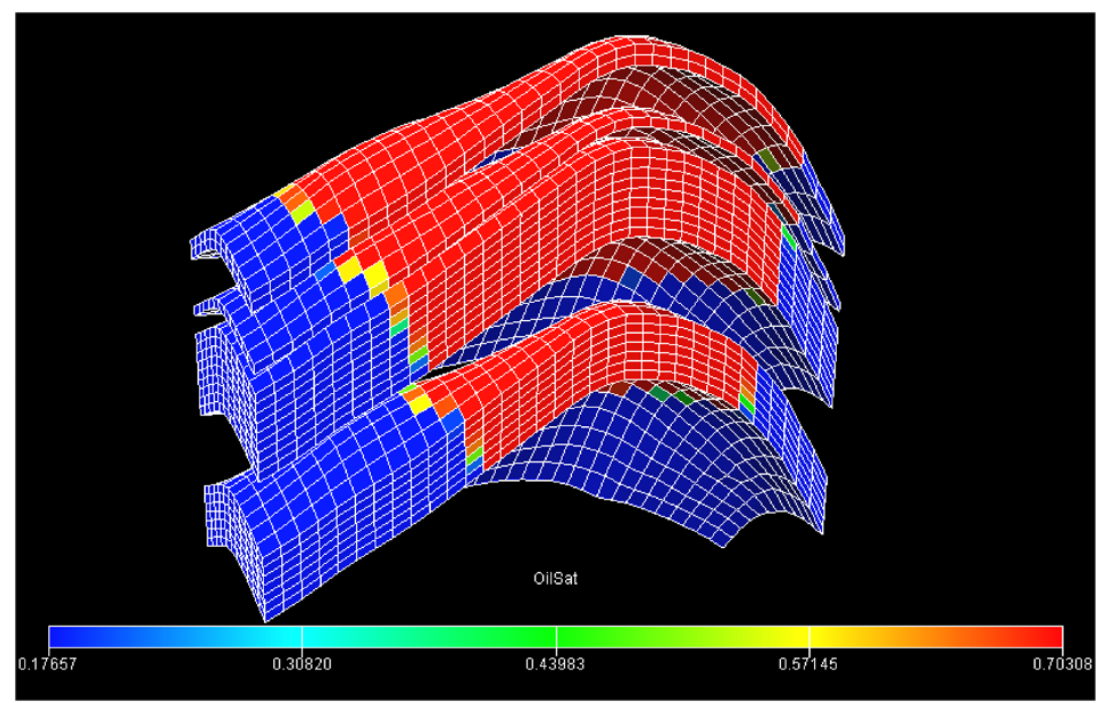

Table 1 Layer properties

\begin{tabular}{lllll}
\hline $\begin{array}{l}\text { Main } \\
\text { layers }\end{array}$ & $\begin{array}{l}\text { Thickness } \\
\text { (ft) }\end{array}$ & $\begin{array}{l}\text { Number of } \\
\text { simulation } \\
\text { sublayers }\end{array}$ & $\begin{array}{l}\text { Average } \\
\text { porosity } \\
(\%)\end{array}$ & $\begin{array}{l}\text { Absolute } \\
\text { permeability } \\
(\mathrm{md})\end{array}$ \\
\hline Upper & 61 & 9 & 18 & 24 \\
Lower & 49 & 7 & 20 & 28
\end{tabular}

Table 2 Geometrical and grid properties of the full model

\begin{tabular}{ll}
\hline Property & Value \\
\hline Model dimensions (ft) & $27,060 \times 17,952 \times 240$ \\
Reference depth (ft) & 10,990 \\
Grid dimensions (ft) & $33 \times 22 \times 35$ \\
Number of active gridblocks & 13,794 \\
Reservoir area (acre) & 4,025 \\
\hline
\end{tabular}

Table 3 Water-oil relative permeability and capillary pressure

\begin{tabular}{llll}
\hline Sw & Krw & Krow & Pcow (psia) \\
\hline 0.3 & 0 & 0.62 & 2.52 \\
0.364 & 0.0088 & 0.48 & 1.26 \\
0.478 & 0.02 & 0.27 & 0.7 \\
0.592 & 0.043 & 0.105 & 0.63 \\
0.706 & 0.105 & 0.04 & 0.4 \\
0.82 & 0.36 & 0 & 0 \\
\hline
\end{tabular}

Production scenarios

\section{Conventional completion}

Controlling the sequence of production events during simulation of each of the two production scenarios
Table 4 PVT data

\begin{tabular}{lll}
\hline Property & Value & Units \\
\hline Gas stock tank density & 0.0635 & $\mathrm{lb} / \mathrm{ft}^{3}$ \\
Gas FVF at $\mathrm{Pb}$ & 1.21 & $\mathrm{RB} / \mathrm{MSCF}$ \\
Gas viscosity at $\mathrm{Pb}$ & 0.0186 & $\mathrm{cp}$ \\
Oil stock tank density & 55.6 & $\mathrm{lb} / \mathrm{ft}^{3}$ \\
Oil bubble point pressure & 2,755 & $\mathrm{psia}$ \\
Oil GOR at $\mathrm{Pb}$ & 0.44 & $\mathrm{MSCF} / \mathrm{STB}$ \\
Oil FVF at $\mathrm{Pb}$ & 1.28 & $\mathrm{RB} / \mathrm{STB}$ \\
Oil viscosity at $\mathrm{Pb}$ & 0.72 & $\mathrm{cp}$ \\
Water stock tank density & 62.4 & $\mathrm{lb} / \mathrm{ft}^{3}$ \\
Water FVF at Pr & 1.0018 & $\mathrm{RB} / \mathrm{STB}$ \\
Water viscosity at Pr & 0.95 & $\mathrm{cp}$ \\
Water compressibility at Pr & $3.2 \mathrm{E}-6$ & $\mathrm{Psi}{ }^{-1}$ \\
\hline
\end{tabular}

Reference pressure of $\operatorname{Pr}=5,700$ psia

(including conventional and intelligent) was the main role of the workflow management software. The conventional scenario was constructed based on sequentially perforating and plugging each of the two zones (see the flowchart in Fig. 8). Production from a layer continued until either a critical maximum economic value for water cut (wcut max $_{\text {ax }}$ ) was exceeded or a lift die-out occurred.

\section{Intelligent completion}

As the requisites for the intelligent scenario, an on/off ICV for each productive sublayer as well as permanent three-phase flow measurement equipment was considered. The intelligent production strategy for a non-commingled flow was to cycle through the oil-containing layers, as displayed by a schematic flowchart in Fig. 9 . 


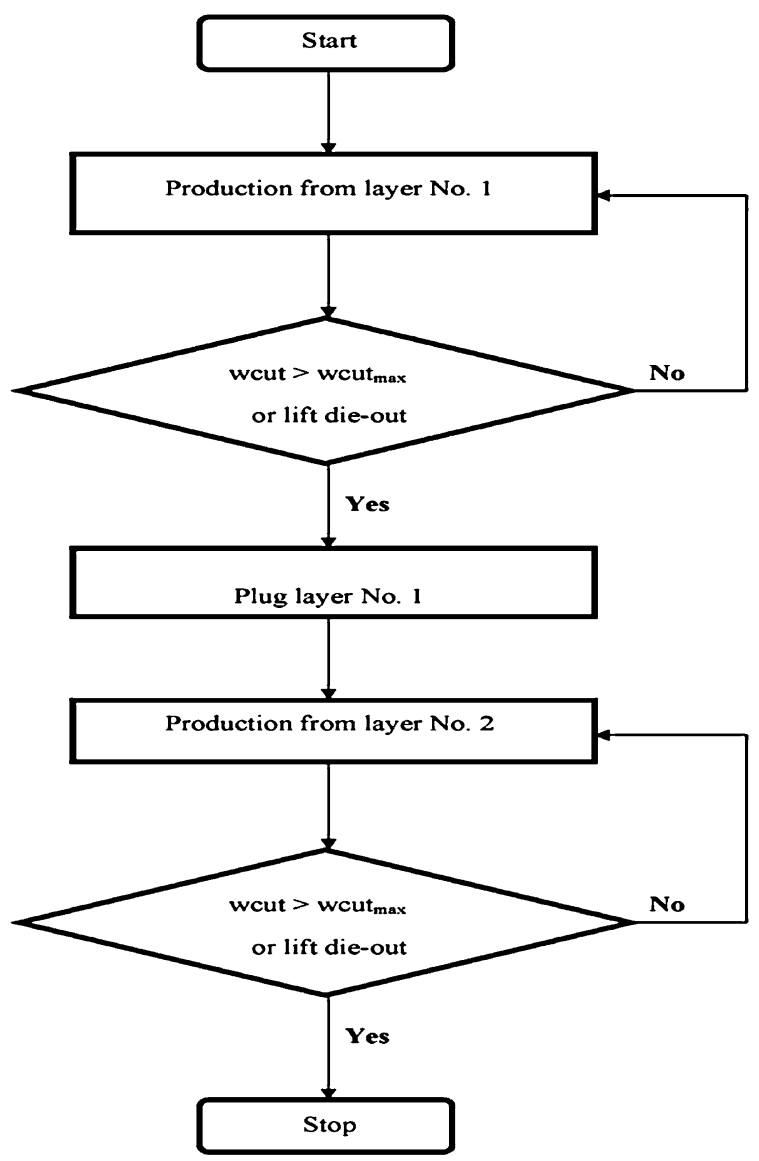

Fig. 8 The flowchart for conventional production

After starting production from the upper layer, the ICVs in that layer were closed when the water cut exceeded a critical medial value $\left(\right.$ wcut $\left._{l i m}\right)$. This value is below the critical maximum economic value for water cut (wcut$\max$ ). A low value was initially assigned to wcut $_{\text {lim }}$ so that production would switch to the next layer as soon as water breakthrough occurred. After completion of a cycle, which is equivalent to production from both oilcontaining layers, the critical medial water cut values

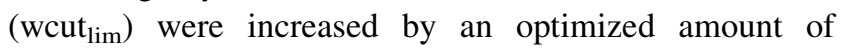
water cut increment. This sequential cyclic process continued until the critical values reached the economic maximum ( wcut $\left._{\max }\right)$.

\section{Economic parameters}

Two operating constraints were considered: (1) a maximum water cut of $40 \%$ and (2) a minimum allowed bottom-hole pressure (BHP) of 3,500 psia. The economic parameters listed in Table 5 were used to compute the incremental NPV of the conventional and intelligent scenarios.

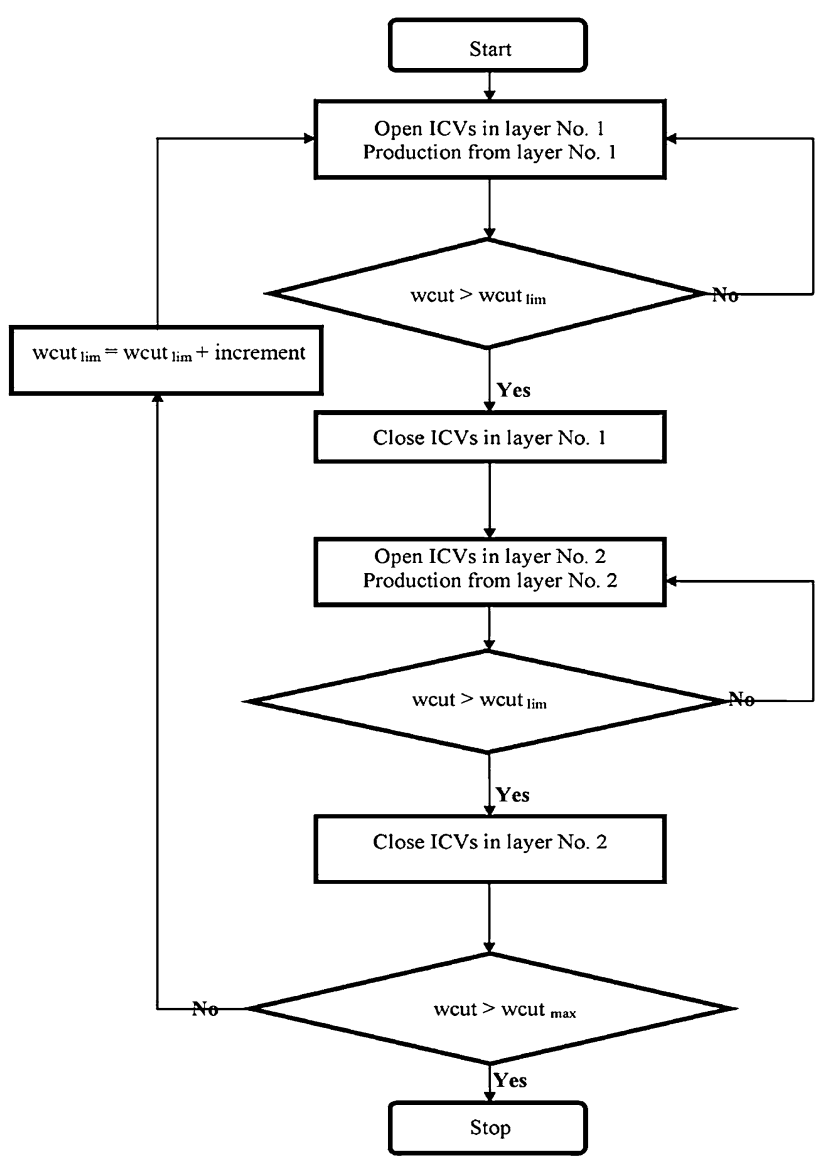

Fig. 9 The flowchart of the control algorithm for intelligent production. Critical values of water cut are incrementally increased in every cycle until their maximum economic value is reached

Table 5 Economic parameters used to calculate NPV

\begin{tabular}{lrl}
\hline Parameter & Amount & Unit \\
\hline Oil price & 100 & \$/STB \\
Water treatment costs & 7 & \$/STB \\
Drilling and completion costs & 10 & $\$ \mathrm{MM} / \mathrm{WELL}$ \\
Intelligent control system costs & 3 & $\$ \mathrm{MM} / \mathrm{ICV}$ \\
Workover costs & 2 & $\$ \mathrm{MM} / \mathrm{W} . \mathrm{O}$. \\
\hline
\end{tabular}

\section{Results and discussion}

This section presents the results obtained from our optimization system for valve control of intelligent wells in a reservoir with real characteristics.

Cumulative production

The path followed by SA algorithm for finding the optimum results, i.e. the highest oil and the lowest water cumulative production is illustrated in Fig. 10. This figure clearly indicates how SA algorithm manages to configure 


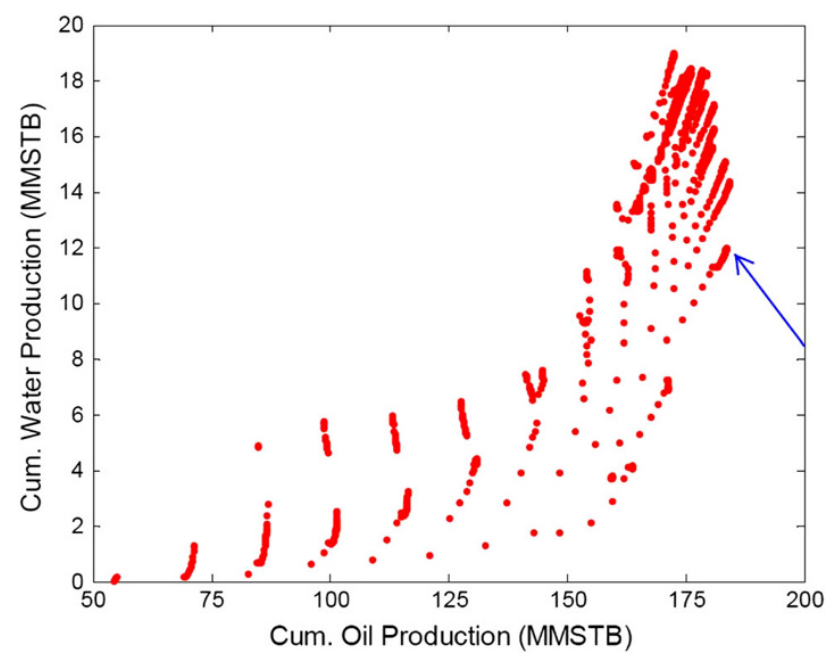

Fig. 10 The path followed by SA algorithm for finding the optimum results, i.e. the highest oil and the lowest water cumulative production

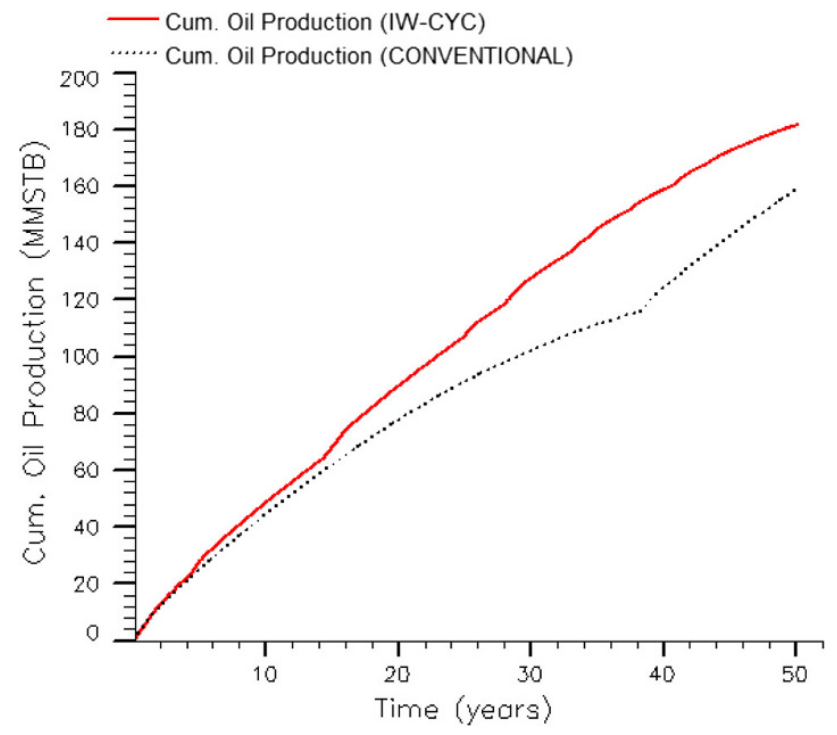

Fig. 11 An increase of 22.17 MMSTB in cumulative intelligent oil production

ICV settings to achieve optimum results for the objective function of NPV.

Figure 11 compares the cumulative oil production in the conventional and intelligent wells. The figure clearly shows that application of the intelligent system has increased the cumulative oil production. The difference between the conventional and the intelligent runs is positive with a magnitude of 22.17 MMSTB, which represents an increase of $13.92 \%$ compared to the conventional case.

Figure 12 depicts a favorable decrease in cumulative water production; the difference between the conventional and the intelligent run is negative with a magnitude of 5.3 MMSTB, which manifests a decrease of $31.89 \%$ in cumulative intelligent water production in comparison with

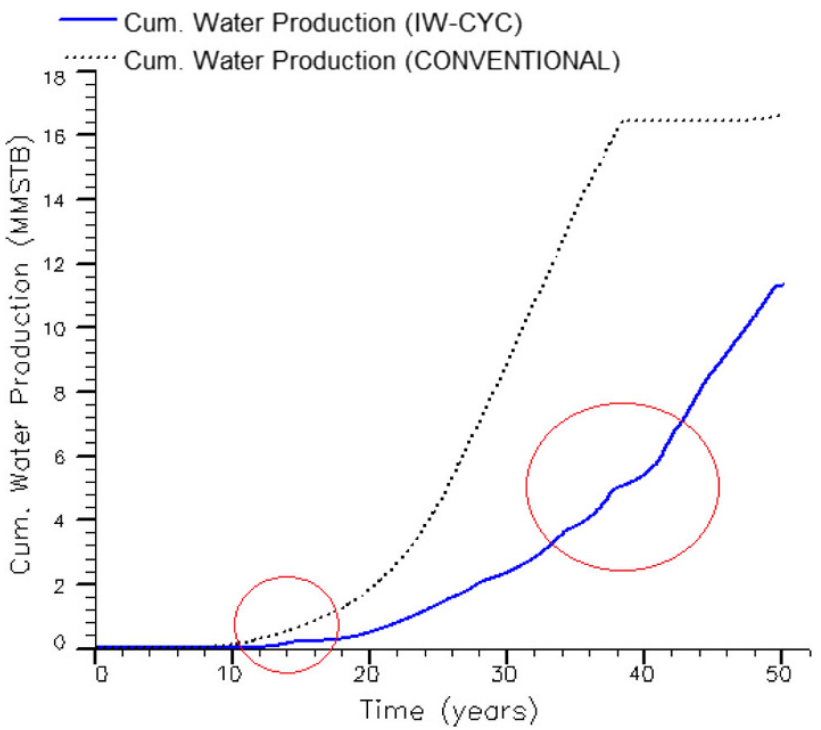

Fig. 12 A 5.3 MMSTB decrease in cumulative water production through intelligent production

the conventional case. Table 6 displays the cumulative production results for both intelligent and conventional scenarios. The intelligent production scenario looks very propitious. Application of the intelligent scenario resulted in a significant increase in cumulative oil production and a decrease in cumulative water production. Production and economic results to compute the NPV of the two scenarios are also given in Table 6, showing an added value of \$MM 2265 in NPV.

The results given in Table 6 indicate that the increased cumulative oil production was the most effective factor contributing to the improved NPV. The remaining added value was owing to the decreased water production and the reduced intervention and workover costs. Due to the relatively low water treatment costs, the contribution of reduced water production to the incremental NPV is not as huge as increased cumulative oil production effect.

In Fig. 13, intelligent cumulative oil production and water cut (solid lines) are compared to conventional cumulative oil production and water cut (dotted and dashed lines, respectively) at the uppermost well connection. Cumulative oil production through the intelligent production is approximately 1 MMSTB higher than the conventional production from the same connection. This is achieved through optimizing water production control and delaying water breakthrough for more than 11 years, as depicted conspicuously in Fig. 13.

\section{Production rates}

The acceleration in production occurs because a single, gradual, and decreasing conventional production from an 
Table 6 Simulation results for intelligent and conventional scenarios

\begin{tabular}{llllccc}
\hline Case & NPV $(\$ M M)$ & Revenue $(\$ M M)$ & Cost $(\$ M M)$ & Cum. W (MMSTB) & Cum. SG (MMMSCF) & Cum. O (MMSTB) \\
\hline IW-CYC & 18,015 & 18,142 & 127.24 & 11.32 & 80.37 & 181.42 \\
Conventional & 15,750 & 15,925 & 174.34 & 16.62 & 70.55 & 159.25 \\
\% Difference & 14.38 & 13.92 & -27.02 & -31.89 & 13.92 & 13.92 \\
\hline
\end{tabular}

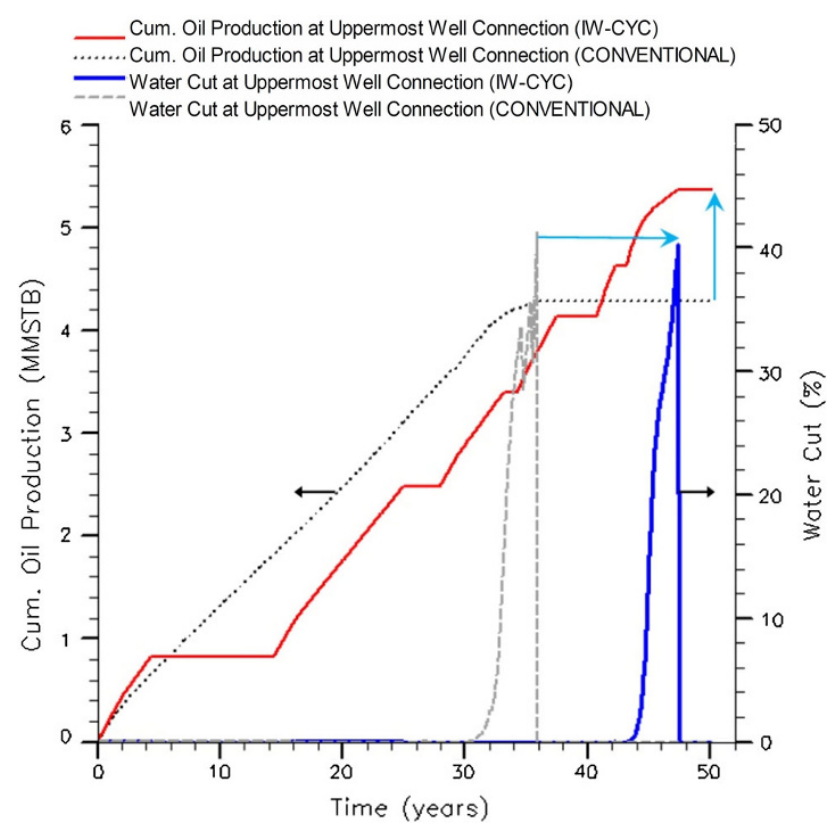

Fig. 13 Cumulative oil production and water cut by the intelligent production (solid lines) compared to cumulative oil production and water cut by the conventional production (dotted and dashed lines, respectively) at uppermost well connection

individual layer is replaced by a cyclic sequential intelligent production from both layers throughout the production time (see Fig. 14).

In conventional production, water-invaded connections are required to be plugged by several workovers (the circle in Fig. 14). Moreover, switching producing intervals in the conventional case requires workover operations, i.e. a plug needs to be installed and the well needs to be re-perforated. However, there are no required workovers for the intelligent case since it is the role of ICVs to control the production in all sublayers. When the critical value of water cut exceeds, the intelligent well is shut-in instantly; however, for a conventional well, a proper reaction usually takes much longer which causes higher water production rates and subsequent inevitable workover operations. Furthermore, the water production plots (Figs. 15 and 16) demonstrate that switching was triggered by reaching the critical value for the water cut. This act of cyclic switching production has been able to control water production significantly (see the circles in Fig. 15) and delay water breakthrough for several years.

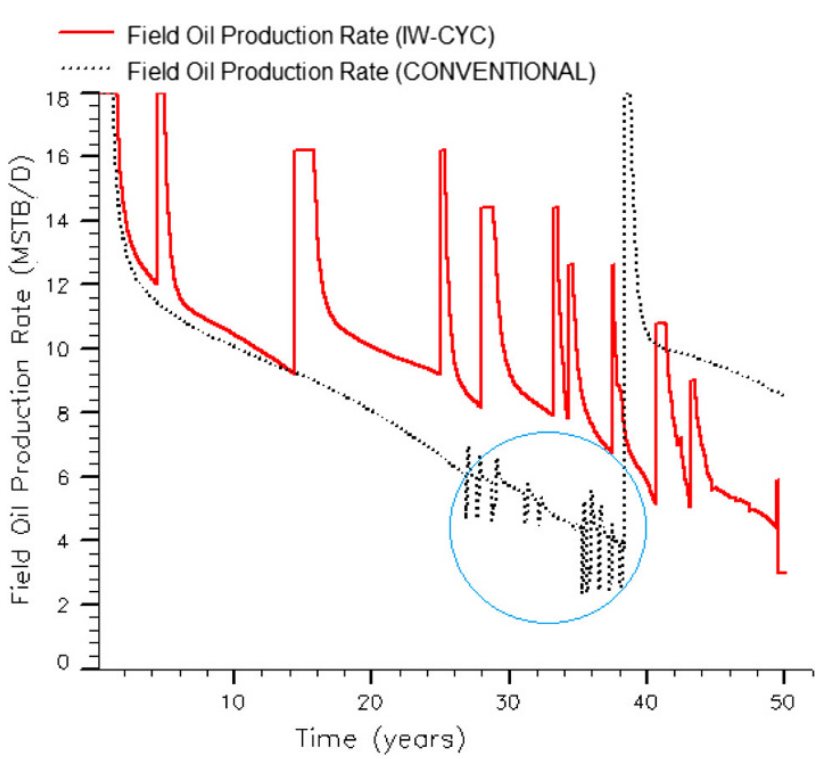

Fig. 14 Production acceleration through frequent switching of on-off ICVs

\section{Conclusions}

In this paper, we modeled and developed a consolidated integrated system for optimizing valve control in intelligent well systems. Simulated annealing, along with a commercial reservoir simulator, was used to model the optimization process. An algorithm-based system was designed which was capable of optimizing intelligent well control to sustain decision-making on whether or not to utilize intelligent well technology. The system was enabled to exploit a commercial reservoir simulator as a simulation engine, which has specific controls for intelligent well completions.

The obtained results indicate that the use of intelligent well completions is significantly profitable because the increase in NPV was highly significant. Increased cumulative oil production was the most effective factor contributing to the improvement in NPV. The remaining added value was owing to the decreased water production and reduced intervention and workover costs, which are considered favorable outcomes, especially in offshore reservoir development. 


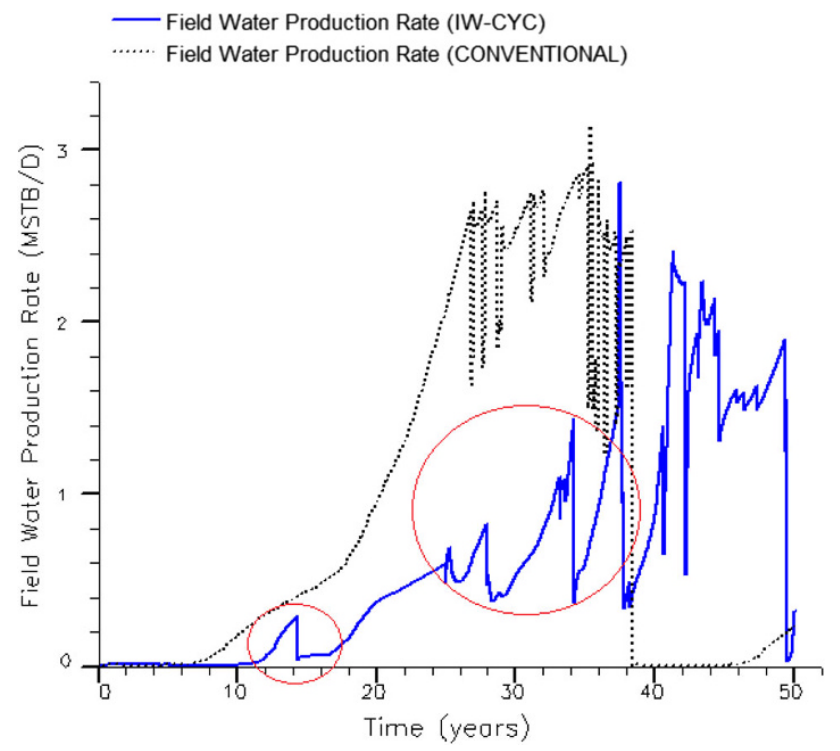

Fig. 15 Water production control through frequent switching of onoff ICVs

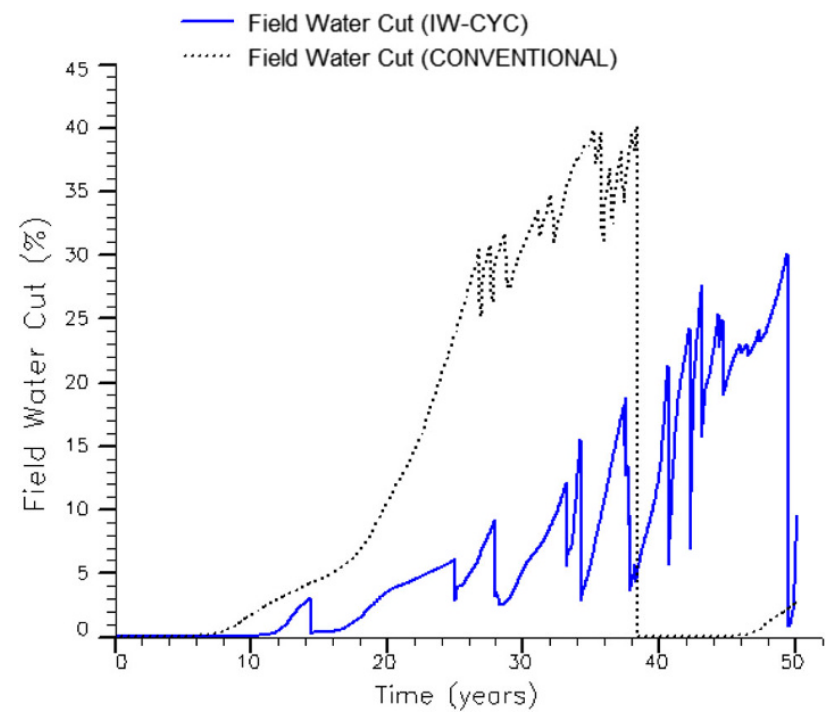

Fig. 16 Water cut control in intelligent production compared to a steep increase in conventional production

Production acceleration and an increase in ultimate recovery are other advantages of producing in a cyclic sequential process. In such a production, the layers are not abandoned forever when a water cut has been reached; instead, they are given the opportunity to go through a pressure build-up. Meanwhile, the water cone is provided with the chance to retreat while the other layers are being produced.

Our concrete results clearly indicate that a global optimization algorithm such as SA can function as a robust and easy-to-use decision support tool not only for determining the feasibility, but also for optimizing the application of intelligent well systems in a given reservoir.

Acknowledgments The authors wish to gratefully acknowledge Iranian Offshore Oil Company (IOOC) management for technical support and permission to publish this paper.

Open Access This article is distributed under the terms of the Creative Commons Attribution License which permits any use, distribution, and reproduction in any medium, provided the original author(s) and the source are credited.

\section{References}

Addagio-Guevera EA, Jackson MD (2008) Insurance value of intelligent well technology against reservoir uncertainty [Conference]. Paper SPE 113918 presented at the 2008 SOE/DOE Improved Oil Recovery Symposium held in Tulsa, Oklahoma, USA, 19-23 April

Akram N, Hicking S, Blythe P, Kavanagh P, Reijnen P, Mathieson D (2001) Intelligent well technology in mature assets. Paper SPE 71822 presented at the SPE Offshore Europe Conference, Aberdeen, 4-7 September

Al-Khelaiwi FT, Muradov KM, Davies DR, Olowoleru DK (2009) Advanced well flow control technologies can improve well cleanup [conference]. Paper SPE 122267 presented at the 2009 SPE European Formation Damage Conference held in Scheveningen, 27-29 May

Brouwer DR, Jansen JD (2002) Dynamic optimization of water flooding with smart wells using optimal control theory. SPE Paper 78278 presented at the SPE European Petroleum Conference, Aberdeen, United Kingdom, 29-31 October

Brouwer DR, Jansen JD, Van Der Starre S, Van Kruijsdijk CPJW, Berentsen CWJ (2001) Recovery increase through water flooding with smart well technology. Paper SPE 68979 presented at the SPE European Formation Damage Conference, The Hague, Netherlands, 21-22 May

Datta-Gupta A, Alhuthali AHH, Yuen B et al (2010) Field applications of waterflood optimization via optimal rate control with smart wells. SPE Res Eval Eng 13(3):406-422. doi:10.2118/ 118948-PA

Dilib FA, Jackson MD, Mojaddam Zadeh A, Aasheim R, Årland K, Gyllensten AJ, Erlandsen SM (2012) Closed-loop feedback control in intelligent wells: application to a heterogeneous, thin oil-rim reservoir in the North Sea. Paper SPE 159550, presented at the 2012 SPE Annual Technical Conference and Exhibition, San Antonio, Texas, USA, 8-10 October

Dolle N, Brouwer DR, Jansen JD (2002) Dynamic optimization of water flooding with multiple injectors and producers using optimal control theory. Paper presented at the 15th International Conference on Computational Methods in Water Resources, Delft, Netherlands, 23-28 June

Doublet DC, Aanonsen SI, Tai X-C (2009) An efficient method for smart well production optimisation. $\mathrm{J}$ Pet Sci Eng 69(1-2):25-39. doi:10.1016/j.petrol.2009.06.008

Ebadi F, Davies DR (2006) Should "Proactive" or "Reactive" control be chosen for intelligent well management [Conference]. Paper SPE 99929 presented at the 2006 SPE Intelligent Energy Conference and Exhibition held at Amsterdam, the Netherlands, 11-13 April

Ebadi F, Davies DR (2006) Techniques for optimum placement of interval control valve(s) in an intelligent well [Conference]. 
Paper SPE 100191, presented at the SPE Europec/EAGE Conference and Exhibition held in Vienna, Austria, 12-15 June

Elmsallati SM, Davies DR (2005) Automatic optimization of infinite variable control valves [Conference]. Paper SPE 10319, presented at the International Petroleum Technology Conference held at Doha, Qatar, 21-23 November

Gai H (2001) Downhole flow control optimization in the world's 1st extended reach multilateral well at Wytch farm. SPE Paper 67728 presented at the SPE/IADC Drilling Conference, Amsterdam, Netherlands, 27 February-1 March 2001

Ghosh B, King P (2013) Optimization of smart well completion design in the presence of uncertainty. Paper SPE 166008 presented at 2013 SPE Reservoir Characterization and Simulation Conference and Exhibition held in Abu Dhabi, UAE, 16-18 September

Glandt CA (2005) Reservoir management employing smart wells: a review [Conference]. SPE Drill Compl 20(4):281-288

Greenberg J (1999) Intelligent completions migrating to shallow water, low cost wells, Offshore International. 66: 63-64

Holmes JA, Barkve T, Lund O (1998) Application of a multisegment well model to simulate flow in advanced wells. Paper SPE 50646 presented at the 1998 SPE European Petroleum Conference, The Hague, 20-22 October

Jalali Y, Bussear T, Sharma S (1998) Intelligent completion systemsthe reservoir rationale. Paper SPE 50587 presented at the European Petroleum Conference, The Hague, 20-22 October

Kharghoria A, Zhang F, Li R, Jalali Y (2002) Application of distributed electrical measurements and inflow control in horizontal wells under bottom-water drive [Conference]. Paper SPE 78275 presented at the SPE 13th European Petroleum Conference, held at Aberdeen, Scotland, 29-31 October

Kirkpatrick S, Gelatt CD, Vecchi MP (1983) Optimization by simulated annealing. Science 220(4598):671-680. doi:10.1126/ science.220.4598.671 (JSTOR 1690046, PMID 17813860)

Metropolis Nicholas, Rosenbluth Arianna W, Rosenbluth Marshall N, Teller Augusta H, Teller Edward (1953) Equation of state calculations by fast computing machines. J Chem Phys 21(6):1087. doi:10.1063/1.1699114
Meum P, Tøndel P, Godhavn J-M Aamo OM (2008) Optimization of smart well production through nonlinear model predictive control [Conference]. Paper SPE112100 presented at SPE Intelligent Energy Conference and Exhibition, Amsterdam, Holland, 25-27 April

Robinson CE (1997) Overcoming the challenges associated with the life-cycle management of multilateral wells: assessing moves towards the intelligent completion. SPE Paper 38497 presented at the Offshore European Conference, Aberdeen, United Kingdom, 9-12 September

Stone TW, Güyagüler B, Bailey WJ, Damas C, Naccache PF, Morton A (2010) Dynamic SAGD well flow control simulation [Conference]. Paper CSUG/SPE-138054, presented at the Canadian Unconventional Resources and International Petroleum Conference, Calgary, Alberta, Canada, 19-21 October

Stone TW, Brown G, Güyagüler B, Bailey WJ, Law DHS (2011) Practical control of SAGD wells with dual tubing strings [Conference]. Paper CSUG/SPE-149352 presented at the Canadian Unconventional Resources and International Petroleum Conference, Calgary, Alberta, Canada, 15-17 November

Valvatne PH (2003) Efficient modeling of nonconventional wells with downhole inflow control devices. J Pet Sci Eng No 39:99-116

Yeten B, Brouwer DR, Durlofsky LJ, Aziz K (2004) Decision analysis under uncertainty for smart well deployment [Conference]. J Pet Sci Eng 44:175-191

Yeten B, Durlofsky LJ, Aziz K (2002) Optimization of smart well control [Conference]. Paper SPE 79031 presented at the 2002 SPE International Thermal Operations and Heavy Oil Symposium and International Horizontal Well Technology Conference held at Calgary, Alberta, Canada, 4-7 November

Yeten B, Jalali Y (2001) Effectiveness of intelligent completions in a multiwell development context [Conference]. Paper SPE 68077 presented at the 2001 Middle East Oil Show held in Bahrain, 17-20 March 